Supporting Information

\title{
Nanocrystalline polymorphic energy funnels for efficient and stable perovskite light emitting diodes
}

Do-Kyoung Lee ${ }^{1, \dagger}$, Yunseop Shin ${ }^{2, \dagger}$, Ho Jin Jang ${ }^{1, \dagger}$, Joo-Hong Lee $e^{3}$,Keonwoo Park ${ }^{3}$, Woochan Lee ${ }^{4}$, Seunghyup Yoo ${ }^{4}$, Jun Yeob Lee ${ }^{1, *}$, Dongho Kim ${ }^{2,}$, Jin-Wook Lee ${ }^{3, *}$, and Nam-Gyu Park $^{1, *}$

†These authors contributed equally to this work.

${ }^{*}$ Corresponding author

${ }^{1}$ School of Chemical Engineering, Sungkyunkwan University, Suwon 16419, Republic of Korea

${ }^{2}$ Spectroscopy Laboratory for Functional $\pi$-Electronic Systems and Department of Chemistry, Yonsei University, 50 Yonsei-ro, Seodaemun-gu, Seoul 03722, Republic of Korea

${ }^{3}$ SKKU Advanced Institute of Nanotechnology (SAINT) and Department of Nanoengineering, Sungkyunkwan University, Suwon 16419, Republic of Korea ${ }^{4}$ School of Electrical Engineering, Korea Advanced Institute of Science and Technology (KAIST), 291 Daehak-ro, Yuseong-gu, Daejeon, 34141 Republic of Korea 

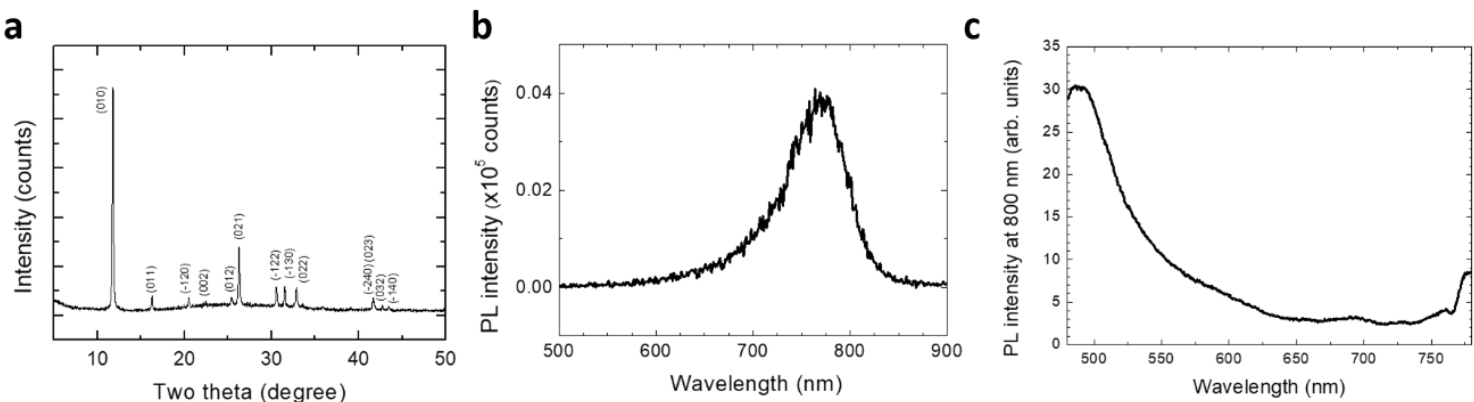

Figure S1. (a) X-ray diffraction (XRD) pattern, (b) emission and (c) excitation photoluminescence spectra of $\mathrm{FAPbI}_{3}$ films after heat-treatment at $80{ }^{\circ} \mathrm{C}$ for $1 \mathrm{~min}$. All the peaks in the XRD pattern were assigned to $\delta$ - $\mathrm{FAPbI}_{3}$ phase.
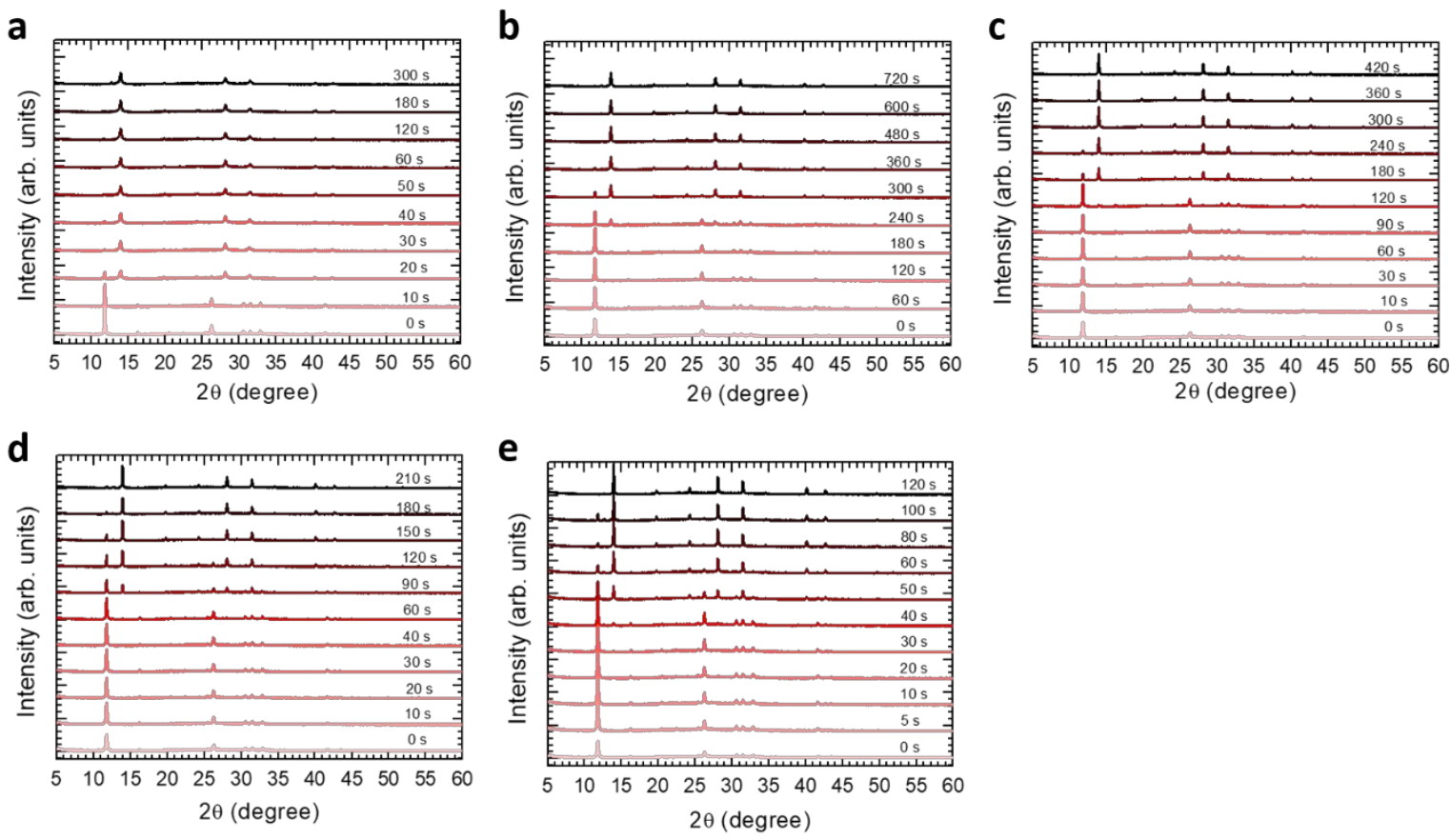

Figure S2. X-ray diffraction patterns of $\mathrm{FAPbI}_{3}$ films without and with addition of 2D perovskite as a function of annealing temperatures and times. The pure $\mathrm{FAPbI}_{3}$ films annealed at (a) $150^{\circ} \mathrm{C}$ (b-e) $\mathrm{FAPbI}_{3}$ films with addition of $2 \mathrm{D}$ perovskite annealed at (b) $150{ }^{\circ} \mathrm{C}$, (c) 160 ${ }^{\circ} \mathrm{C},(\mathrm{d}) 170{ }^{\circ} \mathrm{C},(\mathrm{e}) 180^{\circ} \mathrm{C}$ 

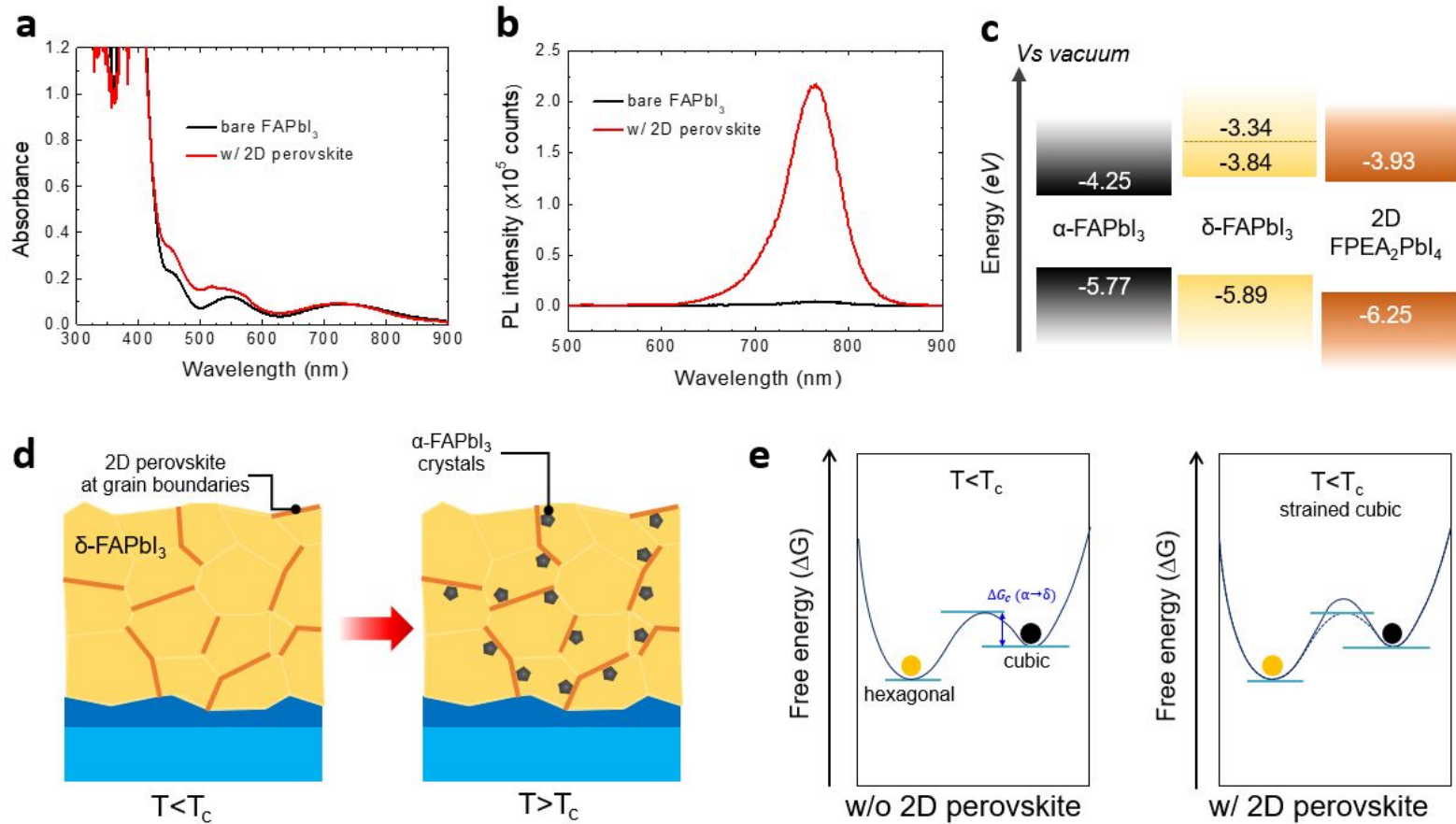

Figure S3. (a) Absorbance and (b) photoluminescence spectra of $\mathrm{FAPbI}_{3}$ films without and with addition of $2 \mathrm{D}$ perovskite. The films were heat-treated at $80{ }^{\circ} \mathrm{C}$ for $1 \mathrm{~min}$. (c) Band structure of $2 \mathrm{D} \mathrm{FPEA}_{2} \mathrm{PbI}_{4}$ perovskite, $\alpha-\mathrm{FAPbI}_{3}$, and $\delta-\mathrm{FAPbI}_{3}$. (d) Schematics showing seeding of $\alpha-\mathrm{FAPbI}_{3}$ crystals at $2 \mathrm{D}$ perovskite $/ \delta-\mathrm{FAPbI}_{3}$ hetero-interfaces (e) Gibbs free energy diagram change with addition of $2 \mathrm{D}$ perovskite.
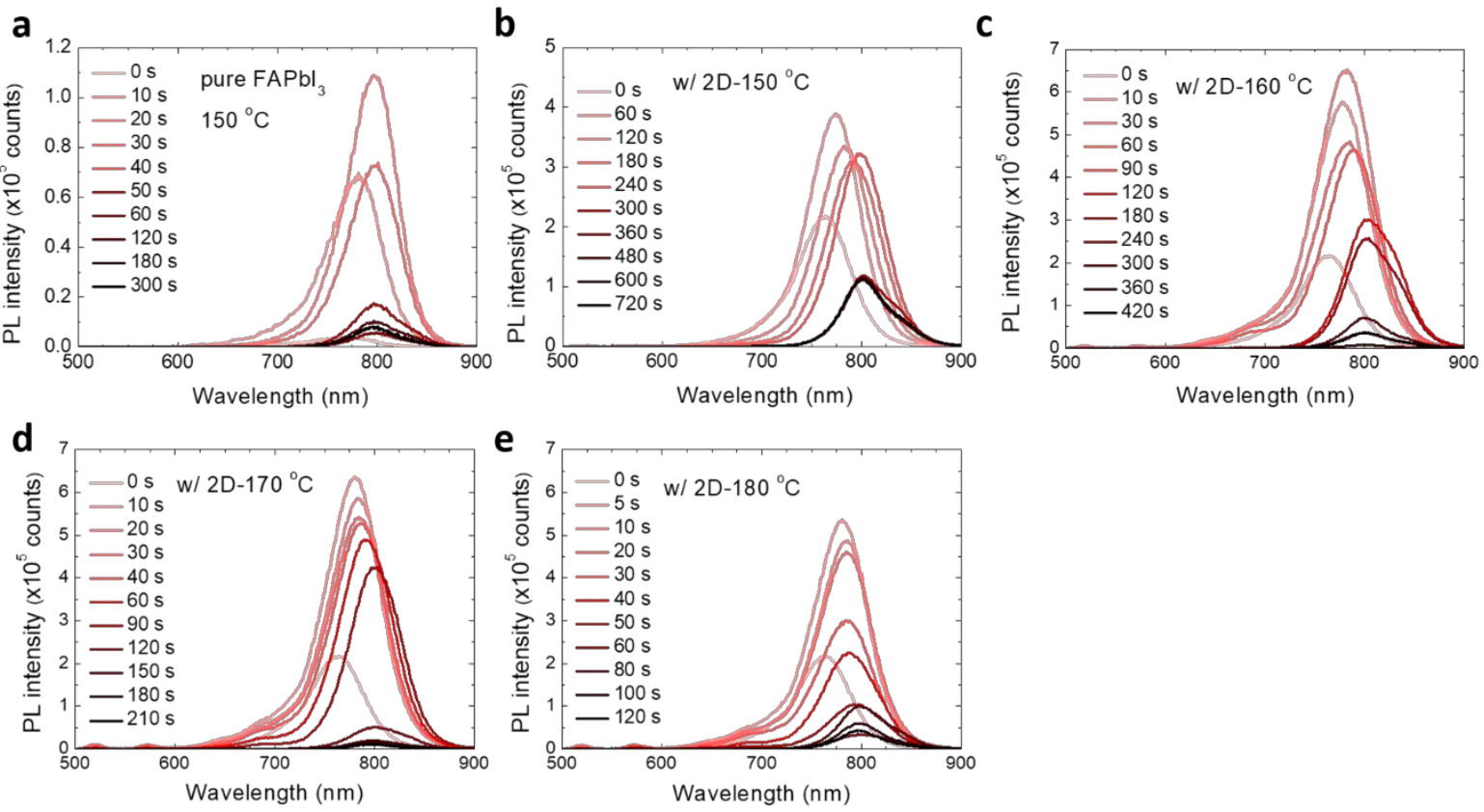

Figure S4. Photoluminescence (PL) spectra of $\mathrm{FAPbI}_{3}$ films without and with $2 \mathrm{D}$ perovskite as a function of annealing temperatures and times. (a) pure $\mathrm{FAPbI}_{3}$ films annealed at $150{ }^{\circ} \mathrm{C}$ (b-e) $\mathrm{FAPbI}_{3}$ films with addition of $2 \mathrm{D}$ perovskite annealed at (b) $150{ }^{\circ} \mathrm{C}$, (c) $160{ }^{\circ} \mathrm{C}$, (d) 170 ${ }^{\circ} \mathrm{C},(\mathrm{e}) 180{ }^{\circ} \mathrm{C}$ 

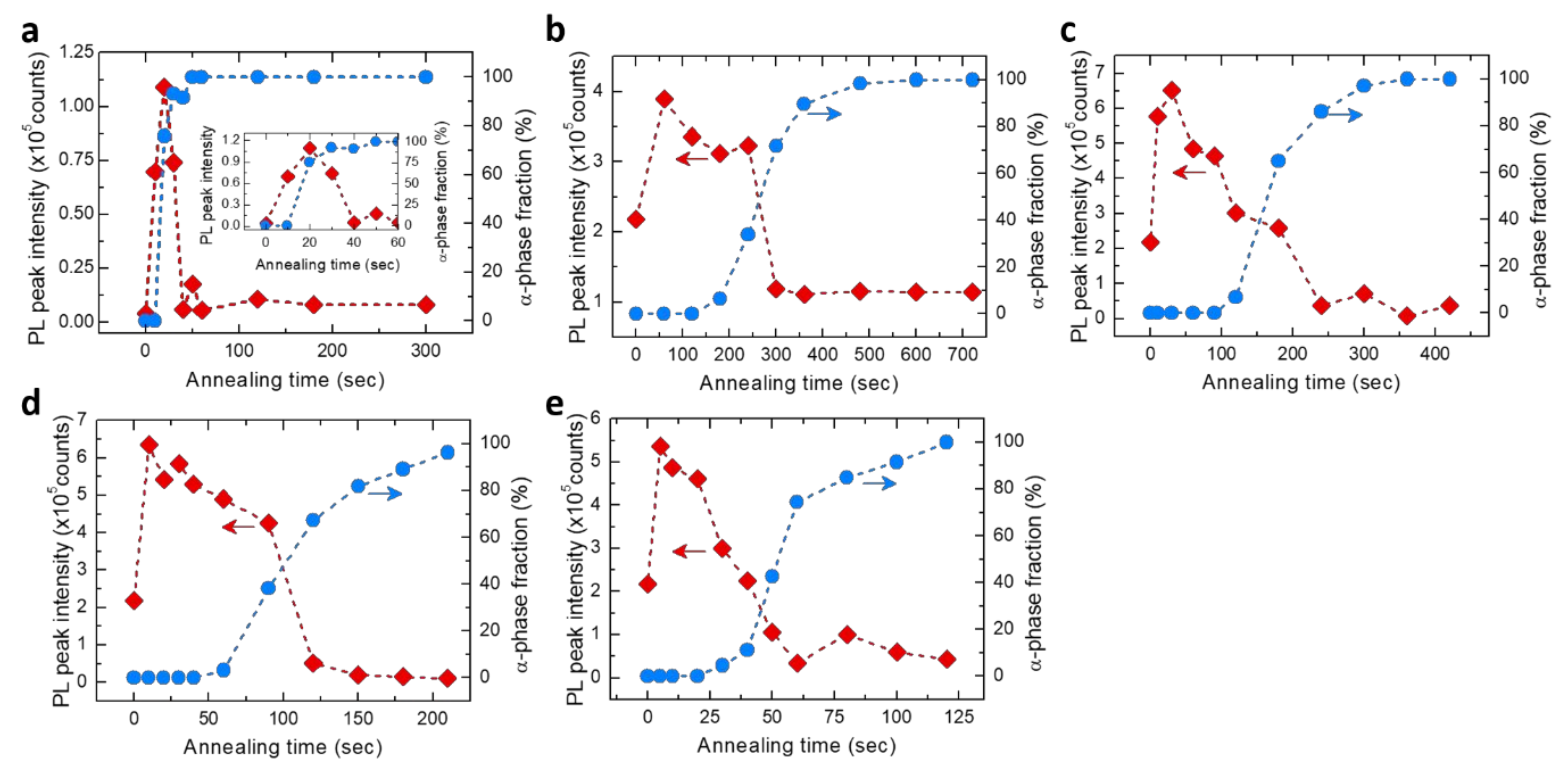

Figure S5. Peak Photoluminescence (PL) intensity and $\alpha$-phase fraction of $\mathrm{FAPbI}_{3}$ films without and with 2D perovskite as a function of annealing temperatures and times. (a) pure $\mathrm{FAPbI}_{3}$ films annealed at $150^{\circ} \mathrm{C}(\mathrm{b}-\mathrm{e}) \mathrm{FAPbI}_{3}$ films with addition of 2D perovskite annealed at (b) $150{ }^{\circ} \mathrm{C}$, (c) $160^{\circ} \mathrm{C}$, (d) $170^{\circ} \mathrm{C}$, (e) $180^{\circ} \mathrm{C}$

a
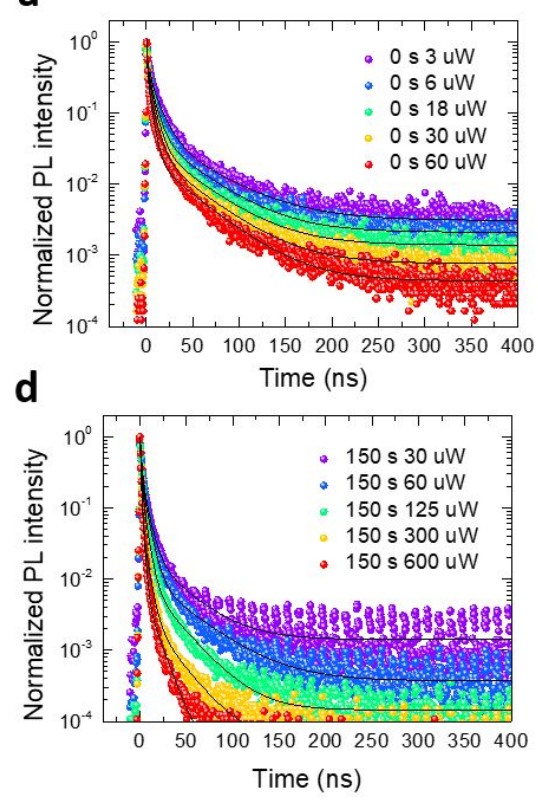

b
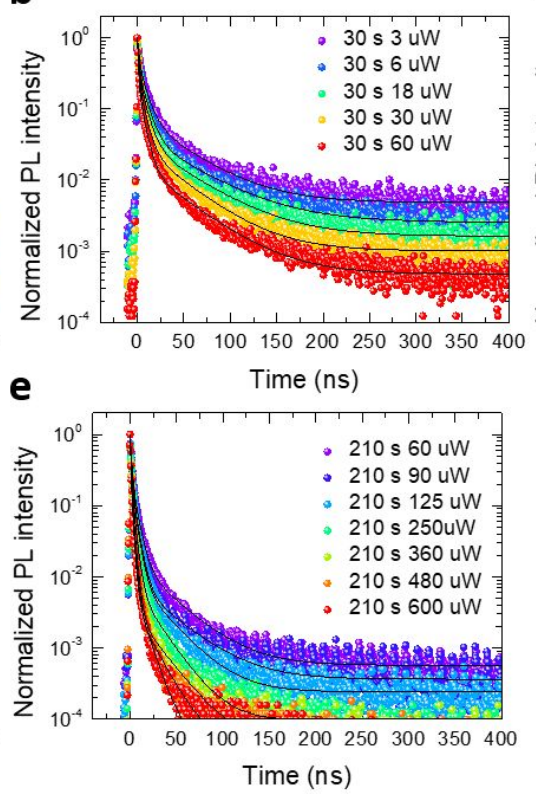

\section{C}

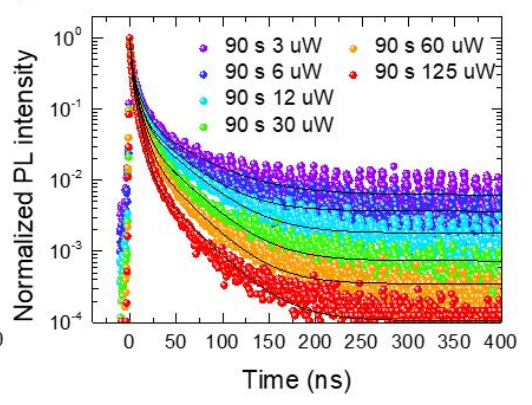

Time (ns)

Figure S6. Time resolved photoluminescence (PL) decay curves of $\mathrm{FAPbI}_{3}$ films with 2D perovskite as a function of annealing time at $170{ }^{\circ} \mathrm{C}$. (a) $0 \mathrm{~s}$, (b) $30 \mathrm{~s}$, (c) $90 \mathrm{~s}$, (d) $150 \mathrm{~s}$, (e) 210 s. Solid spheres and lines are measured data and fitted curves, respectively. 


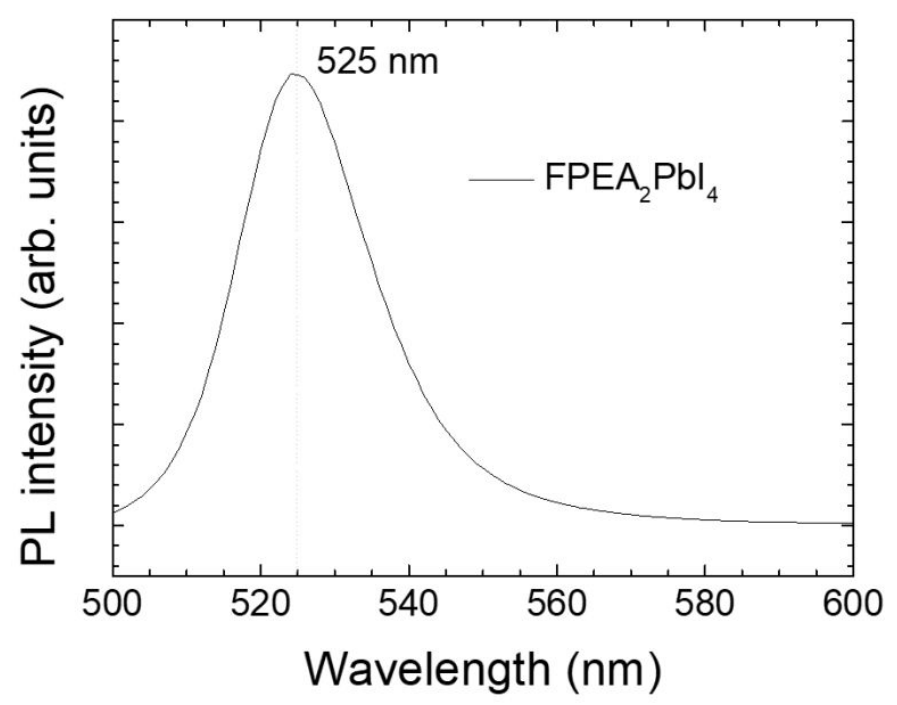

Figure S7. Photoluminescence (PL) spectrum of the $\mathrm{FPEA}_{2} \mathrm{PbI}_{4}$ film.
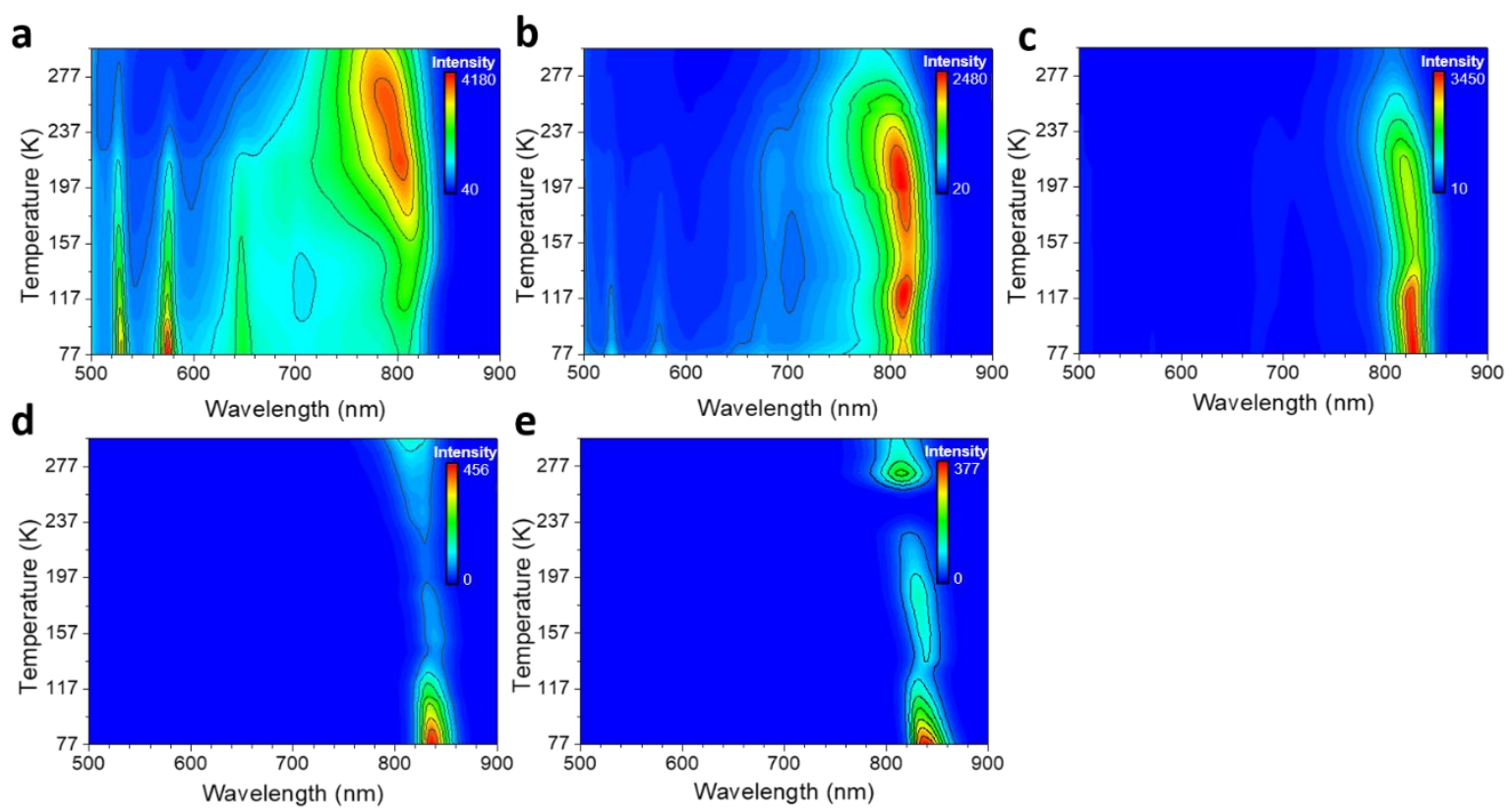

Figure S8. 2D maps of temperature-dependent steady-state PL spectra of $\mathrm{FAPbI}_{3}$ films with 2D perovskite as a function of annealing time at $170^{\circ} \mathrm{C}$. (a) $0 \mathrm{~s}$, (b) $30 \mathrm{~s}$, (c) $90 \mathrm{~s}$, (d) $150 \mathrm{~s}$, (e) $210 \mathrm{~s}$ 

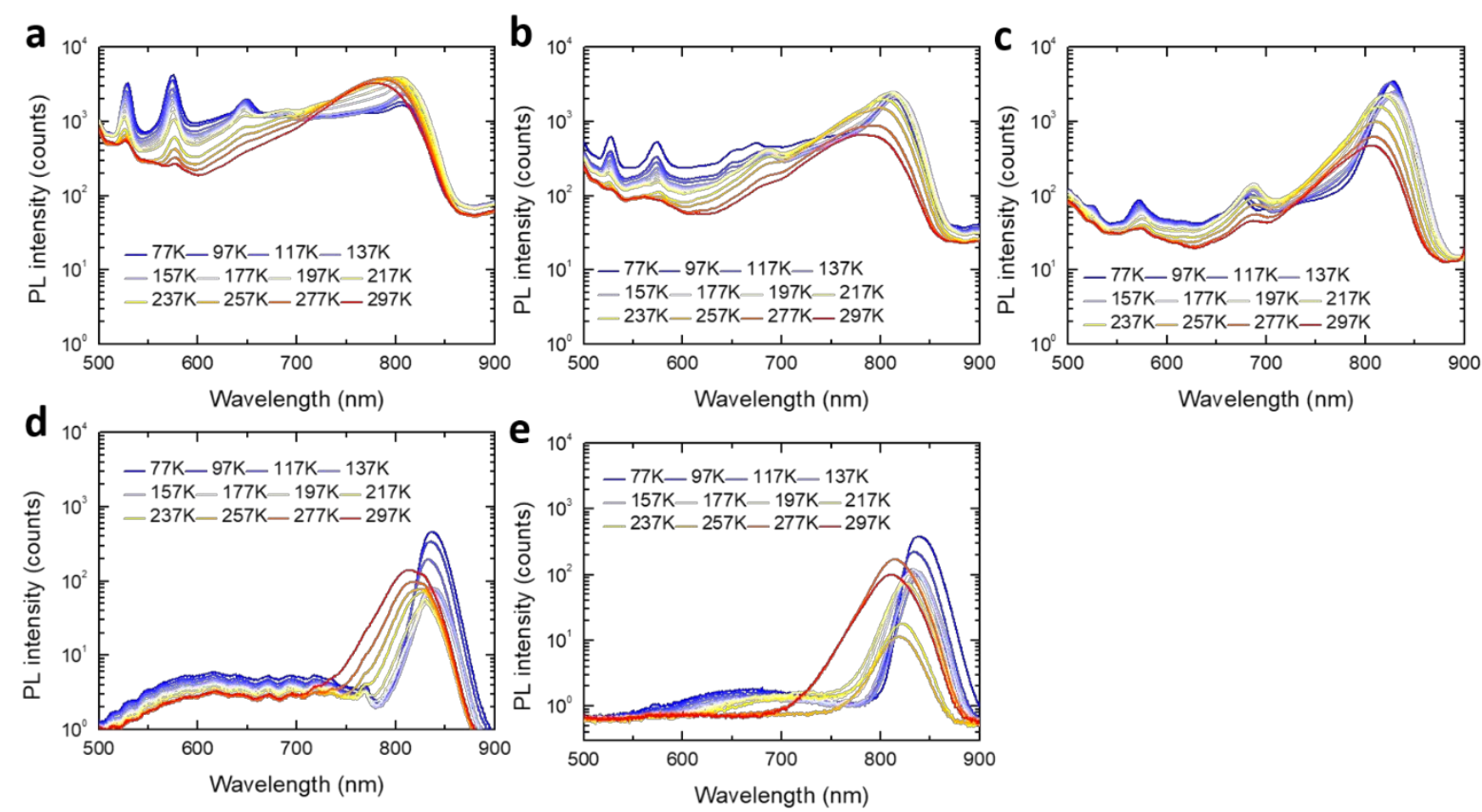

Figure S9. Temperature-dependent steady-state $\mathrm{PL}$ spectra of $\mathrm{FAPbI}_{3}$ films with $2 \mathrm{D}$ perovskite as a function of annealing time at $170{ }^{\circ} \mathrm{C}$. (a) $0 \mathrm{~s}$, (b) $30 \mathrm{~s}$, (c) $90 \mathrm{~s}$, (d) $150 \mathrm{~s}$, (e) $210 \mathrm{~s}$
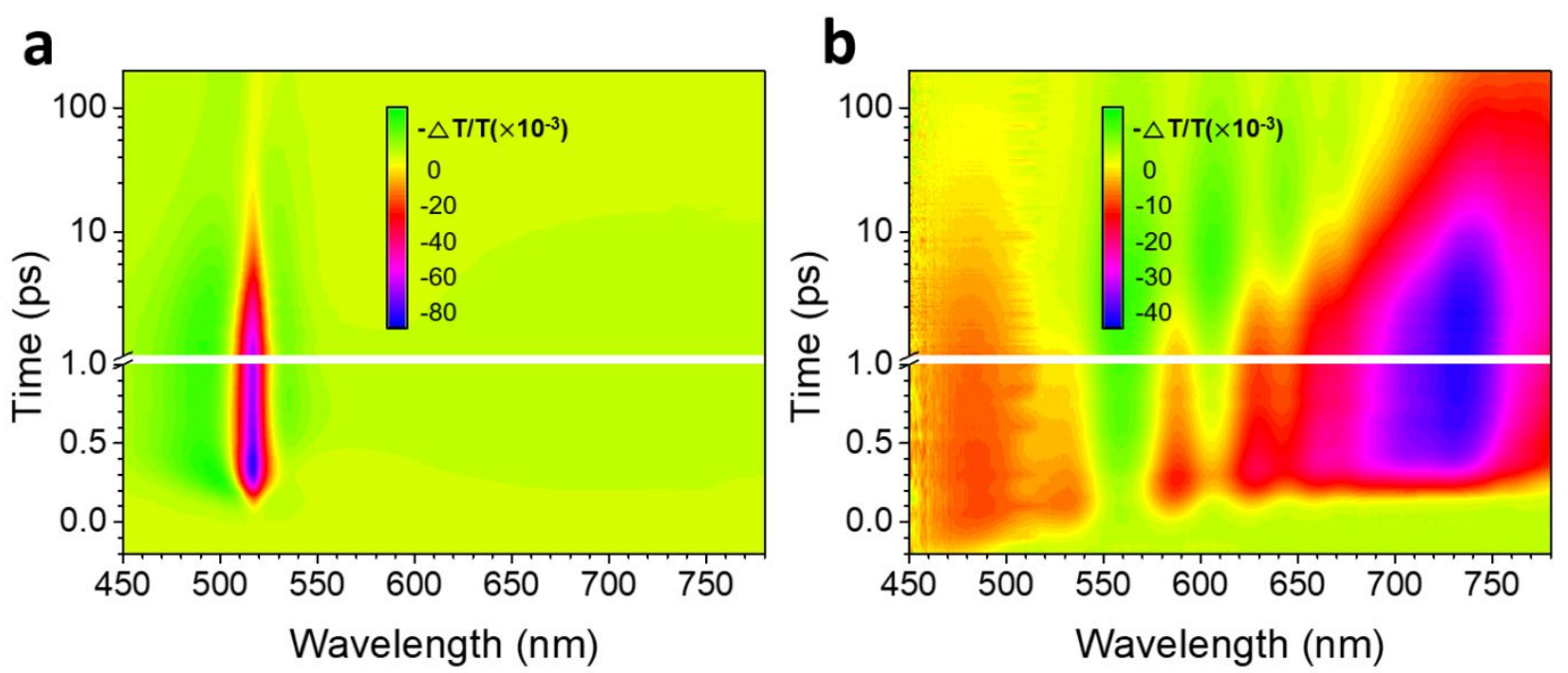

Figure S10. Transient absorption (TA) spectra of (a) 2D perovskite (b) $\mathrm{FAPbI}_{3}$ after annealing at $80{ }^{\circ} \mathrm{C}$ for $1 \mathrm{~min}$ (from -0.2 to $1.0 \mathrm{ps}$ is in linear scale while from $1.0 \mathrm{ps}$ to $200 \mathrm{ps}$ is in logarithmic scale). 

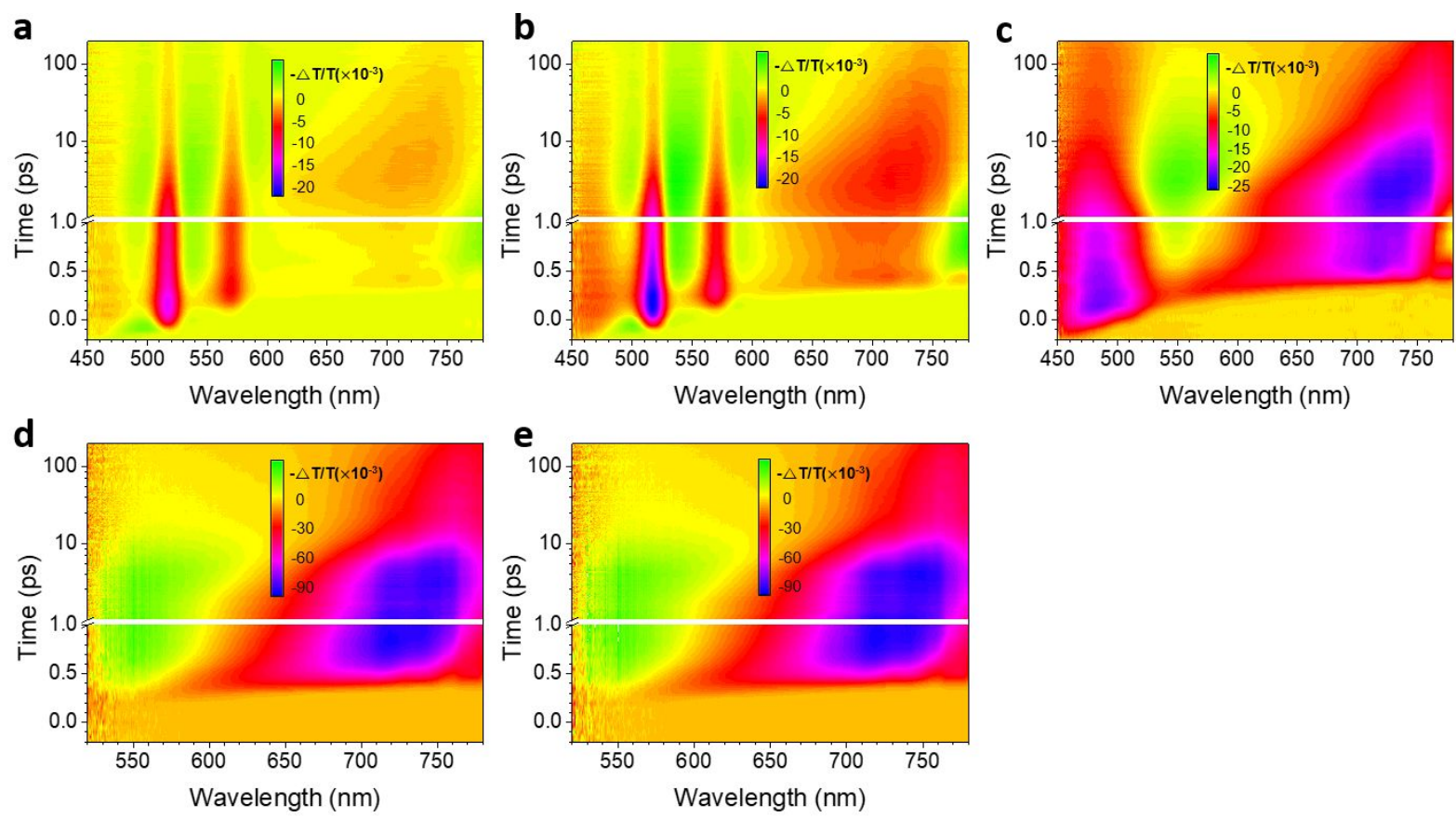

Figure S11. Transient absorption (TA) spectra of $\mathrm{FAPbI}_{3}$ films with addition of 2D perovskite annealed at $170{ }^{\circ} \mathrm{C}$ for different time. (a) $0 \mathrm{~s}$, (b) $30 \mathrm{~s}$, (c) $90 \mathrm{~s}$, (d) $150 \mathrm{~s}$, (e) $210 \mathrm{~s}$ (from -0.2 to $1.0 \mathrm{ps}$ is in linear scale while from $1.0 \mathrm{ps}$ to $200 \mathrm{ps}$ is in logarithmic scale) 

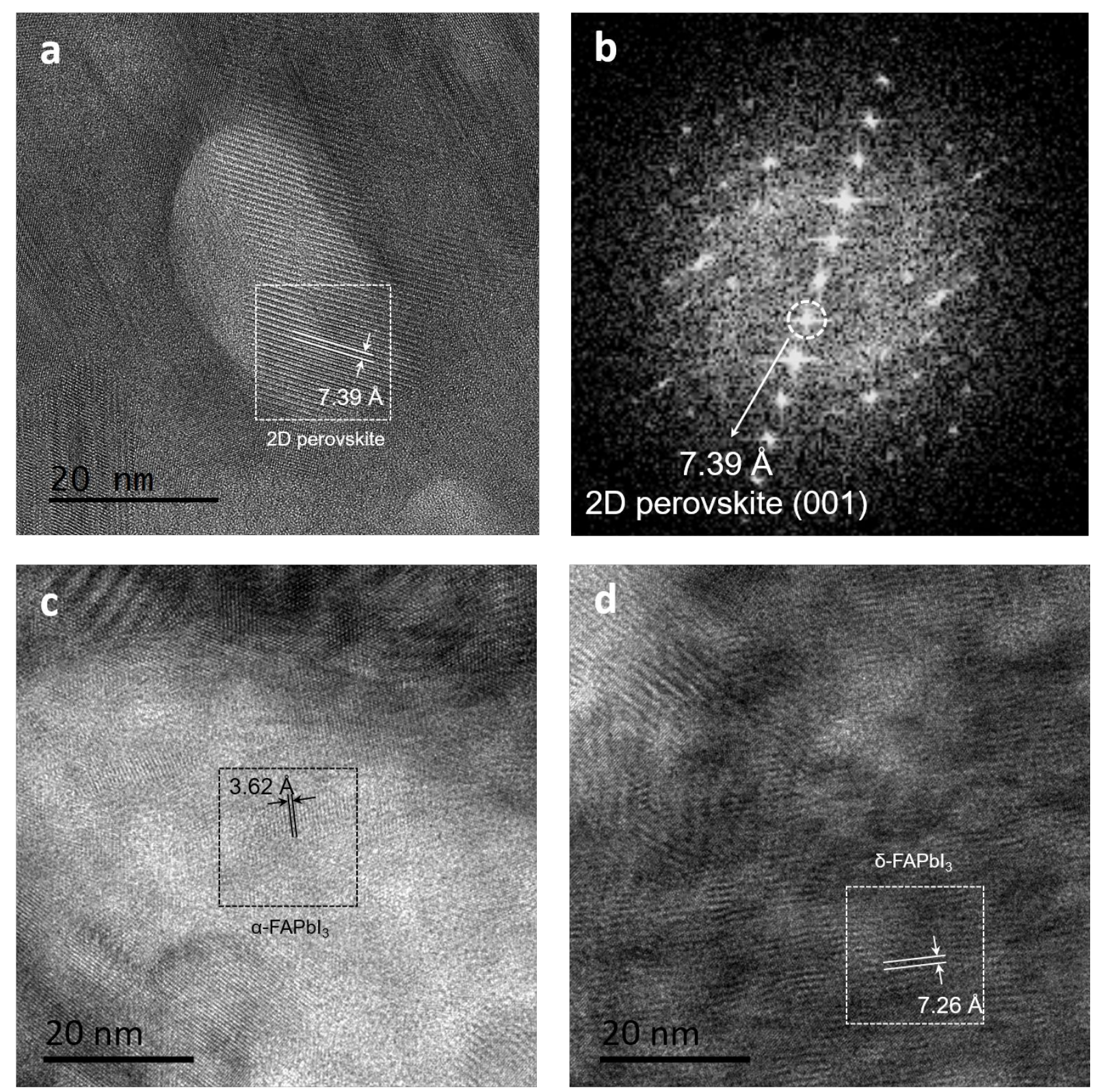

Figure S12. (a) Magnified transmission electron microscopic images of the LED devices based on the $\mathrm{FAPbI}_{3}$ films with addition of $2 \mathrm{D}$ perovskite and annealing for $90 \mathrm{~s}$ at $170{ }^{\circ} \mathrm{C}$. (b) Corresponding fast Fourier transform (FFT) of the regions with white dashed boxes. Enlarged TEM images of Figure $4 \mathrm{c}$; (c) $\alpha-\mathrm{FAPbI}_{3}$ and (d) $\delta$-phase $\mathrm{FAPbI}_{3}$ regions. 

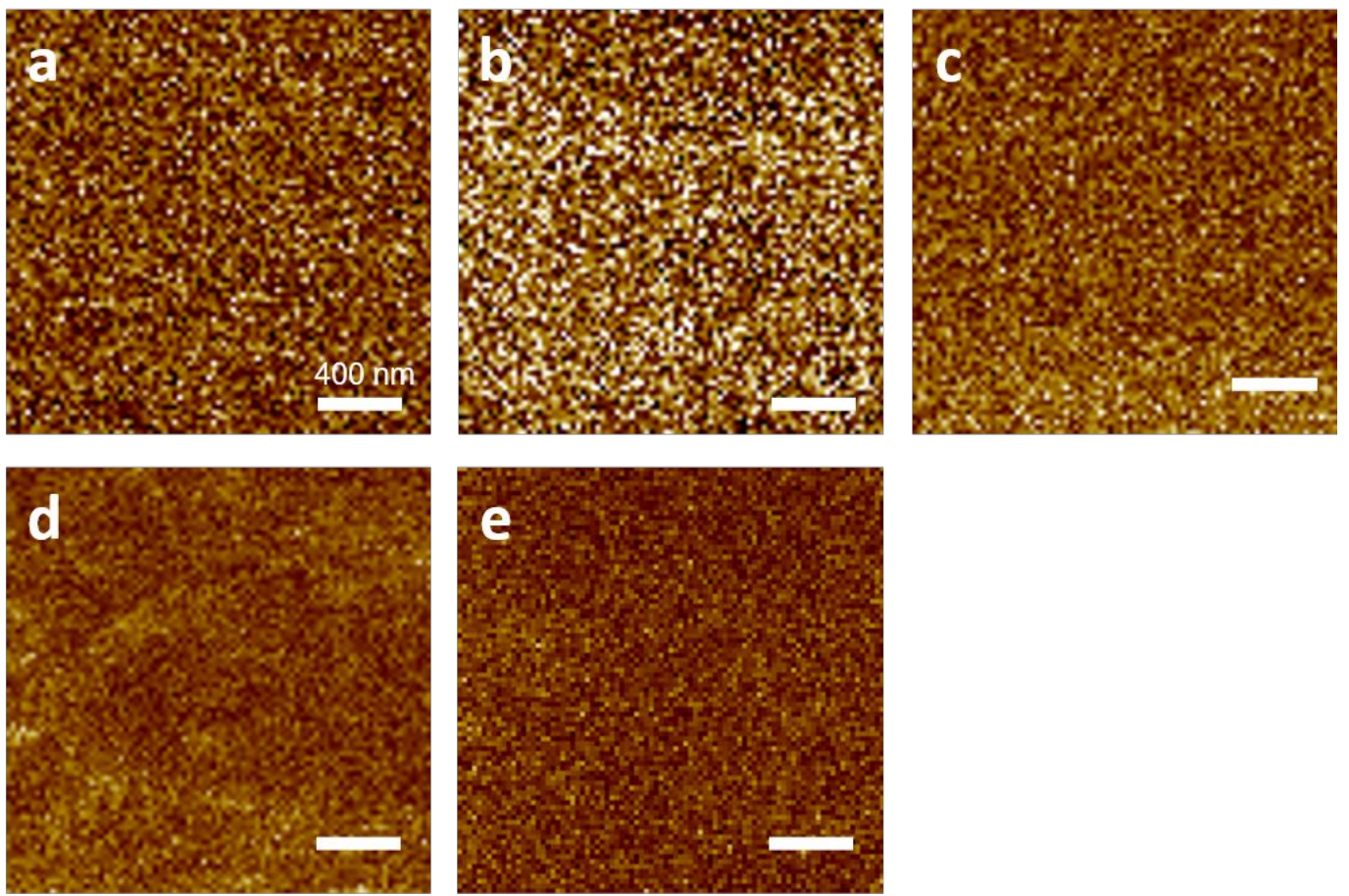

Figure S13. Photoluminescence mapping of $\mathrm{FAPbI}_{3}$ films with addition of $2 \mathrm{D}$ perovskite as a function of annealing time at $170{ }^{\circ} \mathrm{C}$. (a) $0 \mathrm{~s}$, (b) $30 \mathrm{~s}$, (c) $90 \mathrm{~s}$, (d) $150 \mathrm{~s}$, (e) $210 \mathrm{~s}$

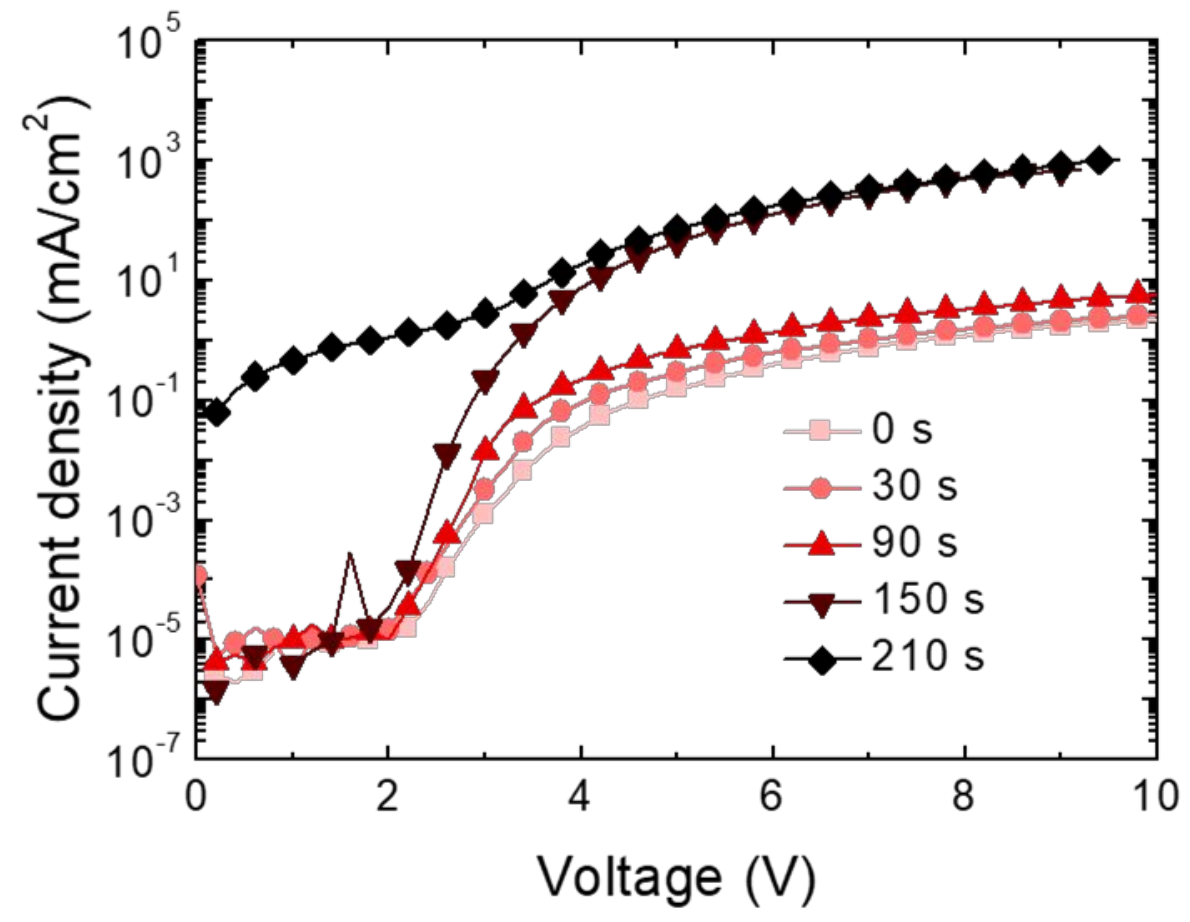

Figure S14. Current density-voltage curves of light emitting diode devices based on the $\mathrm{FAPbI}_{3}$ films with addition of 2D perovskite after annealing for $0,30,90,150$ and $210 \mathrm{~s}$. 

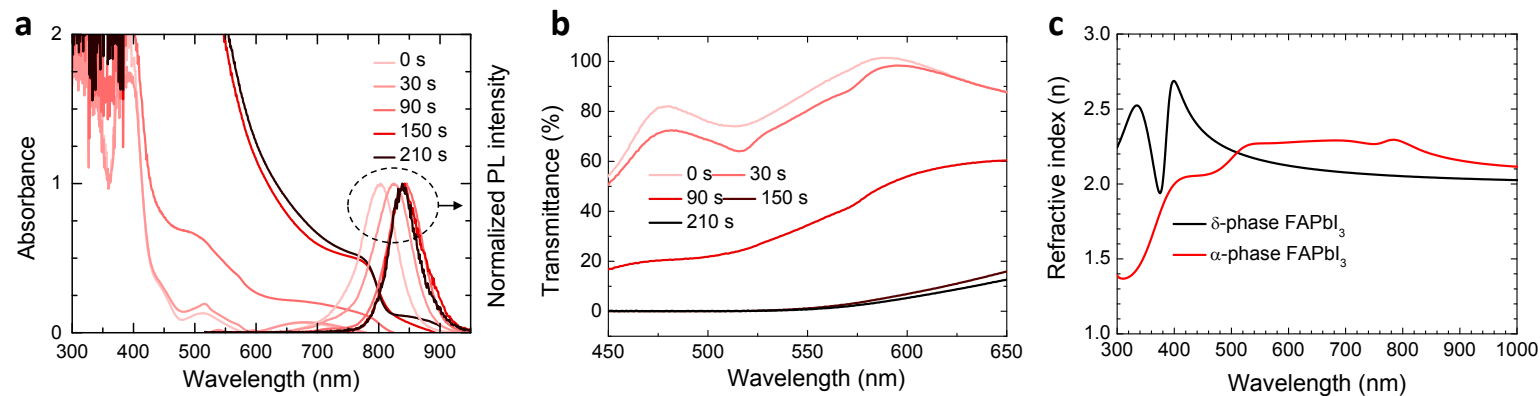

Figure S15. (a) Absorption and normalized photoluminescence (PL) spectra of the $\mathrm{FAPbI}_{3}$ films with addition of 2D perovskite after annealing for 0, 30, 90, 150 and $210 \mathrm{~s}$. (b) Transmittance spectra of the films at visible wavelength region. (c) Refractive indices of pure $\delta$ - and $\alpha-\mathrm{FAPbI}_{3}$ films measured by ellipsometry.

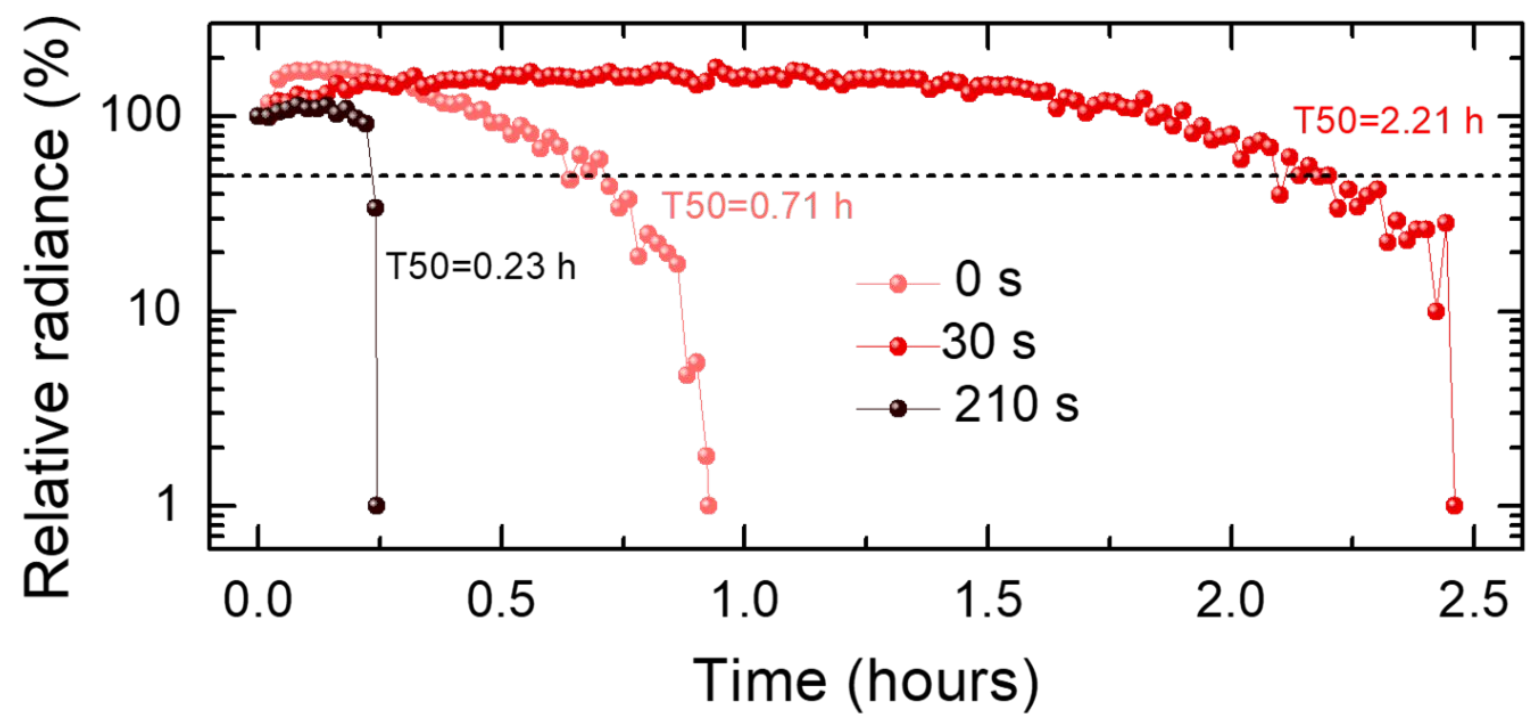

Figure S16. Operational stability of light emitting diode devices based on the $\mathrm{FAPbI}_{3}$ films with addition of $2 \mathrm{D}$ perovskite after annealing for 0,30 and $210 \mathrm{~s}$. The initial radiance of the devices were set to be $\sim 0.2 \mathrm{Wsr}^{-1} \mathrm{~m}^{-2}$. The T50 lifetimes of each device (time at which radiance of the device decays to $50 \%$ of initial value) are marked. 


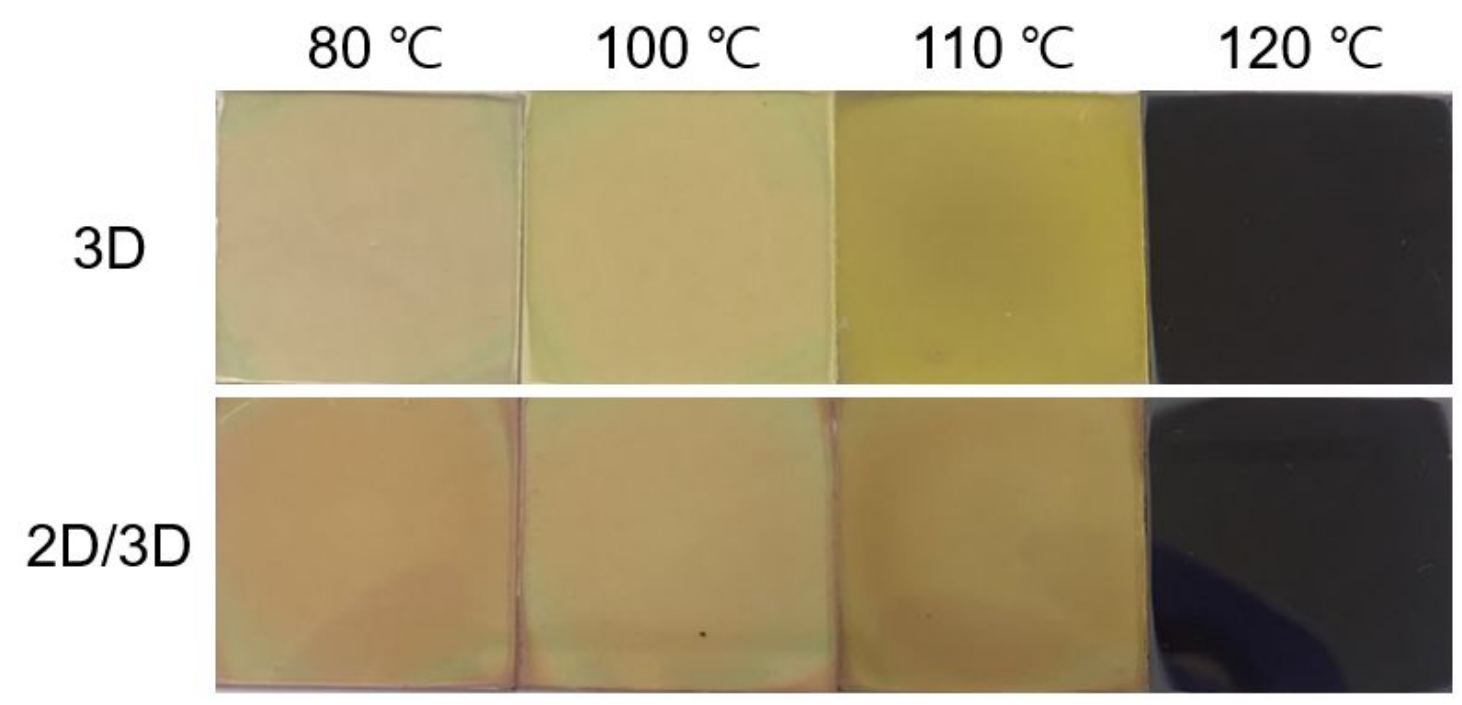

Figure S17. Photos of $\mathrm{FAPbI}_{3}$ films without (3D) or with 2D (2D/3D) perovskite annealed at different temperatures for $1 \mathrm{~h}$.

Table S1. Fitted rise or decay time constants for transient absorption (TA) signals of $\mathrm{FAPbI}_{3}$ films with addition of $2 \mathrm{D}$ perovskite annealed at $170{ }^{\circ} \mathrm{C}$ for $30 \mathrm{~s}$ (Figure $3 \mathrm{f}$ )

\begin{tabular}{ccccc}
\hline & $467 \mathrm{~nm}$ & $517 \mathrm{~nm}$ & $580 \mathrm{~nm}$ & $760 \mathrm{~nm}$ \\
\hline$\tau_{1}(\mathrm{ps})$ & -0.7 & -1.74 & 1.74 & 0.7 \\
$\mathrm{~A}_{1}$ & 61.6 & 73.6 & 82.1 & 55.4 \\
$\tau_{2}(\mathrm{ps})$ & -101 & -10.6 & -2.98 & 2.98 \\
$\mathrm{~A}_{2}$ & 38.4 & 26.4 & 17.9 & 21.5 \\
$\tau_{3}(\mathrm{ps})$ & - & - & - & -127.1 \\
$\mathrm{~A}_{3}$ & - & - & - & 23.1 \\
$\tau_{\text {avg }}(\mathrm{ps})$ & 39.2 & 4.07 & 2.75 & 30.37 \\
\hline
\end{tabular}

